\title{
DIREITO E PSICANÁLISE: UMA RELAÇÃO “ILEGÍTIMA”?
}

\author{
Vassiliki-Piyi Christopoulou'
}

Resumo: Este artigo se propõe estudar alguns aspectos das interações entre direito e psicanálise e seus prolongamentos no campo político sob uma perspectiva epistemológica, histórica e conceitual. Longe de esgotar o assunto, essas considerações buscaram insistir no que resta inexplorado dessa relação complexa, qualificada por muitos como “ilegítima", mas cuja fecundidade e parentescos problemáticos tento demonstrar. Após tornar "legítima" uma colaboração que não parece evidente, e após retomar um Freud que se expressa freqüentemente como jurista, este artigo retoma os limites de tais interações. Pois se a articulação do individual e do coletivo é uma constante na obra freudiana, o método analógico entre processos psíquicos individuais e coletivos, que constituem uma problemática diferente, não encontrou um eco favorável. A hipótese da transmissão de traços mnêmicos nas massas certamente contribuiu para isso. Isto não deveria, contudo, obscurecer o fato que essa parte da obra freudiana mereceria ser mais explorada em suas dimensões metapsicológicas, sociológicas e políticas. Com efeito, a história das idéias e a história da própria psicanálise, enquanto história da produção das obras e dos conceitos, assim como a de seus criadores, só pode se enriquecer com isso, tal como é o caso da Interpretação dos Sonhos.

Palavras-chave: Psicanálise aplicada. História da psicanálise. Psicanálise e política. Psicanálise e direito. Alienação.

\section{Pressupostos epistemológicos}

Fazer dialogar o direito e a psicanálise pode parecer um projeto paradoxal,e, eu estaria mesmo inclinada a dizer,"ilegítimo", dado que a heterogeneidade desses

1 Pesquisadora pós-doc da equipe interna do Laboratório Interactions de la Psychanalise (CEPP) na École doctorale "Recherches en psychanalyse et psychopathologie," Université Paris 7 - Denis Diderot.E-mail:christopoulou.v@wabadoo.fr 
dois campos do saber, com tudo aquilo que eles comportam de incompatibilidades ou de controvérsias diversas, não deixa nenhuma dúvida.

Irei me abster de apresentar aqui uma definição específica da noção de legitimidade. Para seus empregos múltiplos e polissêmicos, eu só poderia indicar-lhes o artigo bastante completo de Jean-Pierre Airut, que assume incontestavelmente uma função propedêutica em relação às contribuições da presente obra (Airut, 2006).

Ora, se não existe diálogo sem controvérsia, a qual mantém juntas a dessimetria e a reciprocidade irredutíveis dos pontos de vista, é também verdade que não há fecundidade num diálogo se este se contentar com uma mera justaposição de posições que nunca se encontram. No entanto, isto não explica o que poderia tornar "legítima" a associação inédita de duas disciplinas que são tão distantes em seus objetivos e em suas problemáticas.

Assim, torna-se necessário precisar alguns pontos para situar minha intenção em um contexto determinado e explicitar seus pressupostos epistemológicos, no intuito de tornar "legítima" essa aproximação.

O domínio em que me situo é o das "interações da psicanálise". Essa noção proposta pela professora Sophie de Mijolla-Mellor está na origem da equipe que tem esse mesmo nome e que foi criada em 1990 no seio da École Doctorale "Recherches en psychanalyse et psychopathologie", que ela dirige na Universidade Paris 7 Denis Diderot. Seus objetivos e suas perspectivas são essencialmente epistemológicos e históricos, confrontando os discursos que mantêm as diversas disciplinas sobre seus objetos e seus métodos, a fim de colocar em foco as interações entre a psicanálise e as Ciências Humanas. Em paralelo, as relações com a AIHP Association Internationale d'Histoire de la psychanalyse (Associação Internacional de História da psicanálise), completam o eixo histórico, incluindo também a dimensão do Direito e da Política. Diferentemente de uma "psicanálise aplicada", muito criticada no passado em razão de um deslocamento para fora de seu lugar de origem e de uma utilização mecanicista e instrumental dos conceitos psicanalíticos, o domínio das interações visa verificar a capacidade do método e da teoria psicanalítica no encontro com outras lógicas, não somente agregando-lhes um novo ponto de vista, mas sendo ela mesma esclarecida, em contrapartida, quanto à sua essência e sua eventual fecundidade. 
A perspectiva é, antes de tudo, epistemológica, interrogando a possibilidade de um empréstimo de modelos, de uma penetração recíproca de conceitos, mas também aquela de uma especificidade dos campos do saber e, eventualmente, sua impermeabilidade. Enfim, questiona os limites dessas interações. (Mijolla-Mellor, 2002, p.1292)

A noção, já muito empregada, de multi- ou pluridisciplinaridade, quando não se limita a uma justaposição de discursos que se ignoram mutuamente ou a uma simples iluminação multifocal, poderia aí associar-se e ser visada, seja através de uma perspectiva interdisciplinar, seja através de uma perspectiva transdisciplinar. Mas a noção de interação proposta por Sophie de Mijolla visa enfatizar que se quer acrescentar algo, a saber, que esses outros domínios pelos quais a psicanálise se interessa foram sempre, e devem continuar a ser, uma parte constitutiva dela mesma. Ou seja, esses campos devem desenvolvê-la e colocá-la constantemente à prova (Mijolla-Mellor, 2004).

\section{Um Freud "jurista”?}

Quando a psicanálise questiona ou é questionada pelo direito, ela necessariamente tropeça em um primeiro obstáculo, uma pedra no caminho muito difícil de contornar: aquela que consiste em querer conciliar a verdade do sujeito em sua singularidade irredutível, enquanto"realidade psíquica", com as exigências de um conjunto de regras exteriores, que regem as relações entre os homens. $E$ se fazendo admitir esse fato por todos, sem exceção, como o que constitui a definição mesma do direito. Eu poderia acrescentar aqui outra dimensão bastante diferente das relações entre direito e psicanálise, que não discutirei neste momento, mas que mereceria ser estudada separadamente. Trata-se da questão da regulamentação, que diz respeito aos psicólogos como conjunto, e aos psicanalistas de uma maneira muito específica.

Apesar da existência da lei de 25 de julho de 1985, revista em 1996, lei que protege e legaliza o título de psicólogo, nada é dito sobre as missões, e o código deontológico não está inserido. A questão de saber o que é uma psicoterapia e quem tem o direito de exercê-la ainda não está totalmente resolvida, levando-se em conta que os psiquiatras e os psicólogos poderiam exercê-la "por direito", sem exigir-se deles uma formação específica, ao passo que os psicanalistas ou os psicoterapeutas, que não têm seu estatuto protegido por lei, poderiam ser excluídos do exercício dessa prática, sabendo-se que eles são os mais habilitados e os mais bem formados nesse campo. Jacqueline Carroy, Annick Ohayon e Régine Plas relatam esse fato em seu Histoire de la psychologie en France (Carroy, 
Ohayon \& Plas, 2006), colocando a ênfase nessa situação paradoxal, muito presente na mídia em 2004, “o que prova que esses debates saíram dos círculos profissionais para tornarem-se um tipo de problema de Estado" (p. 233). A questão do estatuto e das regulamentações da psicanálise na Europa foi, aliás, objeto de estudo de uma recente jornada científica realizada no dia 10 de fevereiro de 2007 pela AIHP, no hospital Saint Anne em Paris.

No entanto, como ressalta Marie-Dominique Trapet (Trapet, 1998, 2002), a psicanálise não pode se desengajar daquilo que funda os valores da sociedade - apesar de seu ceticismo lendário, contrariando diversas crenças produtoras de ilusão, os valores e mesmo a religião são para Freud necessários ao progresso da cultura e ao seu corolário, a renúncia à satisfação direta das pulsões -, e nem renunciar a se interessar pelo direito, o que a leva a formular diferentemente certas questões, em vez de desviar-se delas sob o pretexto de que não dizem respeito a sua "jurisdição"Talvez seja importante precisar aqui que me referirei a uma psicanálise essencialmente freudiana, mesmo que eu possa me referir brevemente a algumas contribuições pós-freudianas maiores, como as de Lacan e de Piera Aulagnier. Trata-se de uma preocupação em voltar às fundações, momento crítico em que a psicanálise é muito atacada e em que é vital realizar o trabalho de um historiador, o que constitui incontestavelmente a melhor maneira de dissipar mal-entendidos que perduram e de apresentar as facetas escondidas de um Freud desconhecido.

A descoberta de um Freud que, aliás, se expressa freqüentemente como um jurista (não se deve esquecer que ele renunciou em sua juventude a uma carreira jurídica, e mesmo a ambições políticas) confere um sentido novo a alguns de seus escritos. De maneira enfática, a utilização de um vocabulário propriamente jurídico nos leva a pensar que o encontro dessas duas disciplinas não é um mero acaso. Basta pensar nas noções psicanalíticas de conflito (konflikt), defesa (Abwehr), juízo de condenação (Verurteilung ou Urteilsverwerfung) e necessidade de punição (Strafbedürfnis) (Assoun, 2002; Pontalis \&"Laplanche, 1967).

Se nós pensamos na instância do "Supereu", neologismo introduzido por Freud em 1923,"a imagem que ele nos apresenta é a de um tribunal que assumiria sozinho o conjunto das funções jurídicas. O Supereu freudiano encontra-se, com efeito, encarregado das tarefas de legislador, de juiz de segunda instância, e talvez até de Corte suprema, de advogado (do Isso), de procurador e mesmo da de consolador" (Trapet, 2002, p. 477). A decomposição da personalidade psíquica revela então uma parte do Eu que se localiza "acima" (über) deste último (Ich), que se opõe a ele, que o julga de maneira crítica exercendo uma certa vigilância sobre ele, controlando-o, e, no caso de ele fracassar, censura-o ao mesmo tempo em que assume uma função de "autoconsolação", a qual se manifesta de maneira notória através do humor. 
O "legislador da psicanálise" se revelará mesmo como aguçado processualista, interessando-se de perto pelo "direito a prova", através da questão da presunção da paternidade, cujos méritos ele ressaltou. Tal questão, crucial no direito e em psicanálise, é examinada por MarieAleth Trapet e Marie-Dominique Trapet, que ressaltam que Freud "reencontra o vocabulário dos grandes processualistas de sua época, que estão, então, debatendo a questão do silogismo jurídico" (Trapet \& Trapet, 1999, p. 55).

Mater certissima, pater semper incertus est. Freud o lembra ao qualificar a passagem do matriarcado ao patriarcado de "progresso da civilização" como "vitória da vida do espírito sobre a vida sensorial", já que esta primeira necessita de operações lógicas e intelectuais superiores, tais como a dedução ou a conjetura, e tem o mérito de permitir a dúvida que vai alimentar as fantasias do "romance familiar". Ele lembra que a maternidade é atestada pelo testemunho dos sentidos, ao passo que a paternidade é uma conjectura (eine Annahme), é edificada sobre uma dedução e um postulado (auf einem Schluss und auf eine Voraussetzung aufgebaut) (Freud, 1939, p. 221). Trinta anos antes, Freud tinha evocado a questão em uma nota de rodapé em "Notas sobre um caso de neurose obsessiva (o homem dos ratos)" (Freud, 1909/1990, p. 251), em que ele evoca igualmente o mito do nascimento de Atena, deusa sem mãe, que surge do cérebro de Zeus.

Por "romance familiar", entendo a construção fantasmática recalcada na qual a criança recria suas origens, imaginando que é oriunda de outro leito ou que é adotada. As crianças se atribuem, com muita freqüência, pais de esferas sociais mais altas, distintas, ricas ou célebres. As operações intelectuais requeridas para essa construção - comparação e relativização - resultam da aquisição, fundamental para o psiquismo, do direito de "duvidar". No que concerne aos efeitos paradoxalmente "benéficos" dessas fantasias, que teriam a tendência equivocada de serem consideradas unicamente como expressão de infidelidade ou de ingratidão dirigida aos pais, Freud é bastante claro em "O Romance familiar do neurótico" (Freud, 1909/1992). Paul-Laurent Assoun retoma essa questão ao denunciar os abusos e os riscos de uma exigência social, crescente hoje em dia, de "provas de paternidade" que os conhecimentos médicos atuais tornaram possíveis (Assoun, 1995).

Freud não hesitará ainda em recorrer novamente a uma metáfora jurídica, talvez mesmo judiciária, intitulando um de seus textos Um sonho probatório (Freud, 1913/1992) - o termo Beweismittel,"meio de prova",é ali utilizado -, para dizer que, para o analista, o sonho pode ter lugar "de confissão disfarçada", e que existiriam mesmo sonhos-confissão sui generis. A "confissão" e a "prova": não poderíamos encontrar nada melhor do que essas duas noções-chave para confrontar psicanalistas e juristas em um questionamento epistemológico comum. Em um número da re- 
vista Topique (Trapet \& Trapet, 1999) pode-se acompanhar como as figuras da confissão no texto freudiano tangenciaram a reflexão sobre a política através da obtenção de confissões pela tortura, reflexão esta dos juristas que reconhecem o lugar privilegiado mas insuficiente da confissão no sistema de provas; lugar oriundo da religião em que a confessio do direito romano (traduzindo a homologeia grega) é, antes de mais nada, uma profissão de fé, subentendendo-se por aí que afirmar sua fé e sua religião implica obrigatoriamente o fato de se reconhecer e de "se assumir" "herege" em relação a um outro.

A publicação de um artigo em 1906, logo após uma conferência no curso do Prof. Löffler, sobre "O estabelecimento dos fatos por via diagnóstica e a psicanálise", e de outra publicação em 1931, “O Parecer acadêmico no processo Halsmann", mostra que, em algumas ocasiões, Freud se debruçou sobre certos aspectos do processo penal, sem procurar, no entanto, exceder-se em teorizações sobre as interações entre direito e psicanálise, fazendo prova sempre de uma certa reserva e de uma extrema prudência sobre o tema. Aliás, a interpretação do primeiro desses dois textos, que trata mais especificamente das relações da psicanálise com a criminologia, foi objeto de muitos contra-sensos no passado. Ele se dirige a futuros juízes e advogados para dar seu parecer sobre um novo método de investigação, capaz de obrigar o próprio acusado a demonstrar, por sinais objetivos, sua culpa ou sua inocência. Freud alerta esses auditores contra as limitações desse método, já que um sentimento de culpa reconhecido não pode em caso algum ser suficiente para incriminar um indivíduo, lembrando que o neurótico se comporta como sendo realmente culpado. No entanto, a noção de "assassinato do pai" e a questão do incesto são tão nucleares em sua obra que tornam inelutável a confrontação das duas disciplinas, mesmo que o "crime" em questão seja, na maioria das vezes, cometido de forma inconsciente e que o processo que se segue não seja outro que aquele da ativação da própria culpa sobre o sujeito. Na verdade, Freud fala muitas vezes de "processo psíquico" pois"o funcionamento da psique apresenta analogias reais com aquele de uma jurisdição, já que se trata de julgar um culpado" (Trapet, 2002, p.477). Outro texto de referência, "Os criminosos por sentimento de culpa" (Freud, 1916), redigido a partir de sua experiência com sujeitos que cometeram um delito durante o tratamento, dá, contudo, um passo a mais. Freud relata que o autor do delito em questão, ou mesmo do ato criminoso, sofria de um sufocante sentimento de culpa de origem desconhecida antes de cometer este último, e que, uma vez que o erro fora cometido,"a opressão havia diminuído, pelo menos o sentimento de culpa se encontrava referido com algo definido". Apesar de reconhecer que esse obscuro sentimento de culpa tinha como origem apenas as intenções criminais em relação ao progenitor do sexo oposto, Freud teve o cuidado de esclarecer que essa categoria de criminosos não representa 
toda a população penal. É por essa razão que a colaboração entre psicanálise e criminologia, cuja fecundidade não é mais contestada atualmente, não deveria nos fazer esquecer a prudente reserva de Freud, que"pode adquirir a posteriori um significado salutar, diante de tantas elaborações precipitadas de uma psicanálise mal aplicada que puderam imprudentemente derivar mecanicamente os atos da fantasia, ou generalizar o recurso ao sentimento inconsciente de culpa, e até mesmo alimentar o sonho de uma psicanálise conquistadora do espaço jurídico" (MijollaMellor, 2002, pp. 381-383).

A título de exemplo do avanço das discussões nessa área, posso apenas referir-me brevemente a colaborações produtivas que atravessaram a história da psicanálise: a Sándor Ferenczi e seus conceitos teórico-clínicos da "identificação com o agressor" ou da "introjeção" deste último, a respeito de uma abordagem psicanalítica da vitimologia, a Daniel Lagache, que dedicou grande parte de sua obra ao diálogo com o grande criminologista belga Etienne De Greeff, aos famosos casos de Jacques Lacan (as "irmãs Papin" e o caso "Aimée"), que o levaram a propor um grupo de "psicoses do superego" para as paranóias de autopunição e de reivindicação, a C. Balier pelo tratamento psicanalítico na prisão e a introdução de consultas médico-legais abertas a psicanalistas e outros.

\section{A articulação do individual e do coletivo: o entrelaçamen- to de duas "legitimidades" distintas?}

Nesta etapa da minha investigação, parece-me pertinente falar de um outro obstáculo que poderia comprometer as relações entre direito e psicanálise que é a conseqüência direta do primeiro.Trata-se da articulação problemática do individual e do social, ou da passagem das considerações que se referem ao indivíduo àquelas que dizem respeito a grupos e sociedades. Esse debate tem sempre suscitado vivas discussões, que não poupam nenhuma disciplina, quer seja a História, a Psicologia Social, a Antropologia ou a passagem da macroeconomia à microeconomia.

Entretanto, a psicanálise freudiana concerne, simultaneamente, ao domínio individual do tratamento e àquele dos fatos coletivos, o qual ocupa quase metade do conjunto da obra do fundador.

Quando se trata de falar de psicologia coletiva, como um trampolim para se falar da história, da sociologia, do direito ou de política, o tertium quid parece ser, para Freud, a família, onde se conjuga o complexo de Édipo. Aqui poderiam me censurar por passar rápido demais do direito stricto sensu à sociologia, às ciências históricas ou à questão da política, campos que, apesar de seus entrelaçamentos, reivindicam, por sua vez, uma autonomia e métodos que Ihes sejam próprios. Além de meus comentários preliminares, eu diria igualmente que o que aparece 
erroneamente como uma "mistura de gêneros" só é a constatação de um laço indissociável de nossas vidas. Essas questões, tanto sob seu aspecto epistemológico quanto sob um ângulo histórico, foram abordadas em minha tese de doutorado, La vérité en Histoire et en Psychanalyse (Christopoulou, 2005).

Depois de Totem e Tabu (1912-13), que é sua primeira grande obra de psicologia social, que responde ao"Presidente Schreber"(1911) e anuncia "Introdução ao Narcisismo" (1914), Freud publica, uma década mais tarde, Psicologia de massa e análise do ego (Massenpsychologie und IchAnalyse) (1921), que é, certamente, sua obra fundamental sobre o tema, enfatizando as relações intrínsecas entre a psicologia individual e a das massas, relações que ele assim mantém ao longo de sua obra.

Nesse belo ensaio, o famoso pessimismo freudiano é unicamente a amarga constatação da volta da barbárie nos países que deram ao mundo os mais altos exemplos de civilização humana. Freud enfatiza a"desilusão causada pela guerra" e termina sua reflexão com uma pergunta:

Por que, para dizer a verdade, os indivíduos-povos se desprezam, se odeiam, se abominam uns aos outros mesmo em tempo de paz, e por que cada nação trata assim as outras? Isto é, certamente, um enigma. Não sei responder a essa pergunta. Nesse caso, tudo acontece como se, a partir do momento em que se reúne uma multidão, até mesmo milhões de homens, todas as aquisições morais dos indivíduos se apagam e só restam as atitudes psíquicas das mais primitivas, mais antigas e mais grosseiras. (Freud , 1921, p. 25, itálicos nossos)

Mesmo se considero que o objetivo de um artigo não é o de apresentar obras já muito conhecidas num espírito "enciclopédico", mas unicamente o de referir-se a elas segundo a necessidade do argumento, permitir-meei dar aqui um rápido panorama de algumas delas que enfatizam a articulação harmoniosa entre o individual e o social e a coerência interna da obra freudiana (cf. igualmente, Porte, 1998).

A segunda sistematização da teoria freudiana das pulsões, formulada em 1920 (pulsões de vida e pulsões de morte), coincide, por outro lado e durante a mesma época, com um desejo de considerar a psicologia social sob um novo ângulo.

Escrita após Para Além do Princípio do Prazer (1920), que, por sua vez, foi redigido depois das Considerações Atuais Sobre a Guerra e a Morte (1945), a obra Psicologia de Massa e Análise do Ego constituiu, nos anos 1920, o segundo momento da grande revisão teórica da qual O Ego e o ld (1923) será o terceiro momento. O Futuro de uma llusão (1927) e O Mal-estar na Civilização (1929) respondem a elaborações e reelaborações da segunda tópica entre 1923 e 1927.

Entre os textos ligados à primeira tópica, O Chiste e Suas Relações com o Inconsciente (1905) constitui, através dos aforismos e jogos de pala- 
vras de histórias judias, uma contribuição ao estudo da cultura judia da Europa central confrontada com o anti-semitismo. De fato, Freud se baseia nas histórias de ghetto para relacionar o mecanismo do sonho e as diversas modalidades do riso.

O artigo "Atos obsessivos e práticas religiosas" (1907/1992) constitui a primeira grande analogia entre psicologia individual e psicologia social, seguido de "A moral sexual religiosa e a neurose moderna" (1908/1989), em que Freud começa constatando que "nossa civilização foi construída sobre a repressão das pulsões" (p. 33), para propor em seguida uma profilaxia social das neuroses. A última obra magistral que fecha esses trabalhos é certamente "O Homem Moisés e a Religião Monoteísta" (1939 [1934-38]), que Freud denomina como sendo seu romance histórico e que versa sobre as origens egípcias de Moisés e a origem dos monoteísmos judeu e cristão, reunindo todos os temas de psicologia social elaborados até então.

Depois de Moisés, Freud escreveu, entre 1930 e 1932, com a colaboração de Bullit, a obra, que se tornou polêmica em função de problemas relacionados à publicação e à difusão do manuscrito, sobre o presidente Thomas Willson, aquele "idealista" que se esforçava em viver na ignorância voluntária das realidades políticas. Freud confessa nesse livro sua antipatia pelo presidente Thomas Willson, que sacrificava incessantemente a realidade em função de "intenções nobres".

Este rápido panorama cronológico e temático enfatiza, particularmente, a incontestável articulação do individual e do social na obra freudiana. Ora, ela não foi menos criticada ou mesmo rejeitada pelos especialistas contemporâneos devido, em parte, ao ato de fé de Freud em relação a Lamarck, no que diz respeito à transmissão de traços mnêmicos entre as gerações. É verdade que a referência à hipótese de Haeckel, segundo a qual a ontogênese recapitula a filogênese, aparece com freqüência sob a pluma de Freud. Mas ela é central e ainda mais importante em Totem e tabu e em Vue d'ensemble der névrose de transfert (1985 [1915]), onde ele esboça um amplo quadro unindo a história da humanidade e a história individual. Ali, Freud é mais lamarckiano do que darwiniano, e sustenta que as aquisições individuais se conservam e se transmitem pelas gerações. Isto não exclui o fato de que o "darwinismo social" que o inspira em Totem e tabu conheceu terríveis desdobramentos e suscitou uma desconfiança justificada. Essas críticas não devem nos impedir de nos beneficiar das preciosas contribuições dessa parte da obra freudiana. É por essa razão que faço questão de retornar à "Massenpsychologie und Ich-Analyse" para explicitar desde já que o objetivo sociológico e político desse ensaio foi paradoxalmente ocultado pelas diferentes traduções aproximativas. Traduzido pela primeira vez para o francês em 1924 por S. Jankélévitch, com o título "Psychologie collective et analyse du moi", e em 1981 por P. Cotet, A. e O. Bourguignon, J. Altounian e A. Rauzy, como 
"Psychologie des foules et analyse du moi", privilegiou-se inicialmente a dimensão quantitativa - que havia sido refutada por Freud - e, em seguida, a noção de "foule", para manter o vínculo com a "Psychologie des foules" de 1895 de Gustave Le Bon, que inspirou o autor. Em 1991, os mesmos autores deram à última versão o título "Psychologie des masses et analyse du moi",em acordo com a opção freudiana (Roudinesco \& Plon, 2000, pp. 853-857). Freud, com efeito, conserva o termo alemão Massen para traduzir a palavra foules de G. Le Bon em vez de empregar Menge, privilegiando, assim, a conotação política. As traduções inglesas não foram bem-sucedidas em traduzir o pensamento subjacente de Freud. James Strachey, ao traduzir o termo alemão Massen por group em vez de mass, optava por uma concepção particular do social, aquela a que a psicologia social norte-americana se voltava e segundo a qual o grupo constituiria o modelo reduzido ou experimental da sociedade.

Desde as primeiras linhas de sua obra, Freud recusa a clássica oposição entre psicologia individual e psicologia social ou das massas, considerando que o "outro", seja este entendido como modelo, como objeto de amor ou como rival, está sempre presente na realidade psíquica do indivíduo.

A questão do "outro" nos conduz àquela da "alteridade", noção lógica e metafísica de ordem muito geral que não interessa à psicanálise a não ser através do uso lacaniano do termo (o grande Outro e o pequeno outro) que ultrapassa de longe as indicações dadas na obra freudiana. Quando me perguntam "o que pensa aquele que considera o outro como legítimo" (eu agradeço a Guillaume Bernard e Jean-Pierre Airut por nossas trocas sobre o assunto), eu não posso fazer nada além de me referir prioritariamente ao famoso grande Outro lacaniano, que designa, alternativamente, toda a potência da lei, o pai admirado, uma força superior imaginária, uma instituição, Deus..., e assim por diante. Esse Outro, supondo que seja ele que "legitima" os atos, as diversas produções e mesmo as intenções e os pensamentos de um ser humano, pode estar na origem dos atos mais nobres, bem como dos mais abjetos. Freqüentemente, os seres humanos aceitam se oferecer como exemplo para cumprir fins que eles julgam superiores à sua pessoa. Sentem que devem servir a uma causa, contribuir através de um tipo de auto-apagamento e ocupar o lugar que o Outro lhes assinalou... Esse grande Outro ao qual se submetem voluntariamente é a garantia da Lei. (cf., sobre o assunto, M. Bertrand \& G. Raimbault, citados por Maître, 1995.) A psicanálise francesa contemporânea esteve igualmente seduzida pela elaboração filosófica e moral dessa noção de Outro, proposta por Emmanuel Levinas. Para voltar a Freud, seu artigo "Personagens psicopáticos em cena" (1942 [1905-1906]) toca nessa questão indiretamente, através de uma peça do dramaturgo austríaco Hermann Bahr, A Outra, peça que coloca um espantoso "jogo de alteridade", o qual Freud, no entanto, não fez nem mesmo constar em seu comentário. 
Mas quando o sujeito não pode mais se reconhecer a menos que seja através da passagem por um Outro (conhece-se o destino filosófico dessa problemática em Hegel e Marx), os riscos de alienação, inerentes a todo discurso ideológico, emanado deste último, começam a perfilar-se. As análises de Freud sobre o famoso "culto da personalidade" do dirigente ou do chefe, que ele compara ao hipnotizador, são, nesse sentido, atualmente clássicas. Esse discurso, como Weltanschauung, visão de mundo, no sentido de uma formulação dogmática dos ideais de uma classe, de um partido, de uma associação ou de uma igreja, visa explícita ou implicitamente a uma dominação cultural, política, econômica, intelectual ou espiritual da sociedade e dos indivíduos. A finalidade de toda ideologia, segundo Freud, será soldar em um sistema de representações defensivo um "coletivo", quer seja a Nação, a Igreja, o Exército ou o Estado.

Essas observações sobre a noção de alienação, que recobre campos tão diversos quanto a psicologia coletiva, a paixão amorosa ou a toxicomania, serão desenvolvidas e redefinidas de uma maneira muito pertinente por Piera Aulagnier, como desejo de aceder a um estado desprovido de todo tipo de conflitos, um estado "a-conflitual",e portanto ilusório, entre o Eu e seus ideais (cf. Aulagnier, 1979). Esse estado

repousa sobre um encontro entre o desejo de auto-alienação e o desejo de alienar o outro. Aquilo que procura, então, desaparecer na alienação, é a tensão engendrada pela diferença.

Lá onde o neurótico difere a realização idealizada de si mesmo e onde o psicótico a coloca como já ocorrida em um modo delirante, o sujeito alienado a transfere sobre um outro que lhe assegura, por procuração, a certeza, a ausência de dúvida e de conflito concernentes a tal realização. (Mijolla-Mellor, 2002, p. 40)

\section{A postura freudiana sobre o político e a política na tormen- ta da modernidade vienense: uma sociedade"doente de di- reito"?}

Em face, pois, dos perigos da alienação do sujeito, Freud se posiciona como homem das luzes, um Aufklärer, denunciando a censura e as mentiras do Estado, que trata os cidadãos como menores de idade. Sua"indiferença" política e a recusa de uma identidade política para si e para a psicanálise são, pois, algo diferente de uma "neutralidade" (cf. Assoun, 1990).

Ele se posiciona, por conseqüência, ao lado de certa influência de pensamento 
que, longe de ver no Estado o cumprimento da história (Hegel), o apresenta como um parceiro sobressalente, idéia onde se encontram traços de Schopenhauer e Nietzsche. Essa posição assinala uma disjunção entre'a política' - fundada sobre uma filosofia da história - e "o político" - reduzido a uma dimensão imanente (Assoun, 1990a, p. 160)

No entanto,"modernos" que somos, tendo vivido o essencial da"revolução freudiana",descobrimos que se uma dualidade desse gênero pode se revelar alienante - refiro-me às minhas considerações precedentes sobre a relação com o Outro - é porque não há o Outro como terceiro e intermediário, que evitaria tanto o afrontamento mortal, em espelho, quanto a "absorção" por uma outra consciência. Não é a figura do poder ele mesmo que transparece aqui em filigrana?

Mas é sobre a guerra que os escritos freudianos parecem nos dizer respeito ainda hoje, exprimindo um engajamento que se quer pacifista.É paradoxal, mas realmente em conformidade com as suas descobertas, com respeito ao pulsional, que Freud apresente esse pacifismo não como uma escolha filosófica, mas como uma atitude que ele nomeia "orgânica" e mesmo "constitucional." Em uma carta a Einstein, ele se diferencia das formas idealistas do pacifismo, ao falar da dita "intolerância constitucional" do kulturmensch.

Quanto à aliança entre freudismo e marxismo, que também foi muito comentada, pode-se dizer que se Freud não deixou de sublinhar nas Novas Conferências de Psicanálise o mérito do materialismo histórico, enquanto explicitação perspicaz das pressões econômicas, por outro lado, ele contestou a "filosofia da história" hegeliana que o fundamentava, mesmo despojado de seu idealismo (Assoun, 1987). Ao final do capítulo $\checkmark$ de Psicologia das Massas e Análise do Eu, ele exprime sua desconfiança pelo socialismo, em uma passagem que mostra que sua lucidez não foi desmentida pela evolução do comunismo, mas igualmente pelos diversos dogmatismos científicos, que conduziriam, segundo ele, ao mesmo resultado, se pudessem tocar um número maior de pessoas:

Se um outro vínculo junto à massa tomar o lugar do vínculo religioso, lugar a que parece atualmente que o laço socialista chegará, isto resultará na mesma intolerância àqueles do exterior, qual nos tempos das guerras religiosas, e, se as diferenças dos pontos de vista da ciência tivessem porventura uma importância análoga para as massas, seria igualmente por esse motivo que o mesmo resultado se reproduziria (Freud, 1921, p. 160)

Mas se há um lugar onde política e psique se misturam e se confundem de maneira totalmente diversa, interrogando uma nova articulação do individual e do coletivo, esse lugar é incontestavelmente a Interpretação dos Sonhos. As questões que tratarei aqui parecem as menos contes- 
táveis, pois trata-se de um outro aspecto do problema: aquele que mistura"história privada" e"história pública" ou a"grande História" (cf.Plon, 2007; Stern, 2004).

Essa" psico-arqueologia",como a chamou de maneira pertinente Carl Schorske (Schorske, 1983), mistura harmoniosamente três níveis distintos: profissional, político e pessoal. Verdadeira "pesquisa do tempo perdido", essa auto-análise de Freud através da apresentação de seus sonhos conjuga-se com a exposição implícita de uma crise política, que cresce quase permanentemente, com o aumento do anti-semitismo e com as frustrações profissionais que ele engendra. Com efeito, dos duzentos vinte e três sonhos relatados, quarenta e sete são dele e cento e setenta e seis provieram seja de pacientes, seja de seu entorno. Por razões de comodidade, ligadas à natureza de uma exposição escrita, Freud escolheu relatar seus próprios sonhos como material de trabalho, mesmo que isto implicasse necessariamente uma discrição em relação a todos os sonhos que trataram de sua vida íntima e de membros de sua família. O sonho"A injeção de Irma" é o exemplo inaugural e um dos mais importantes do livro, comentado em treze páginas por Freud e retomado dezenas de vezes por psicanalistas de todas as escolas. Como a auto-análise de Freud, ele tornou-se um mito, cumprindo a função de um tipo de "romance familiar" das origens e da própria história da psicanálise.

Quando, com a idade de 45 anos, Freud foi tardiamente nomeado como Freierdozent - o que lhe dava o direito de ministrar cursos na Universidade-,apresentou essa promoção a Fliess, em estilo de paródia,comparando-a a um triunfo político:

A aprovação pública foi conquistada. Chovem felicitações e flores, como se a sexualidade tivesse sido de repente oficialmente descoberta por Sua Majestade, a significação dos sonhos confirmada pelo Conselho de Ministros e a necessidade de uma terapêutica psicanalítica da histeria reconhecida pelo Parlamento por uma maioria de dois terços. (Freud, 1902, p. 306)

Os famosos chistes de Freud traduzem, como os sonhos, os atos falhos e os sintomas, os desejos recalcados,"realizando-os"de uma maneira insólita, revelam ao mesmo tempo a"solução"do problema. Nessa época, a realidade da vida política era a imagem contrária daquele Parlamento imaginário de Freud. A paralisia que reinava era tal que o Reichstrat austríaco tinha sido incapaz de encontrar uma maioria simples, sem falar em dois terços, para legislar em qualquer domínio que fosse.

Nessa mesma carta endereçada a Fliess, no entanto, Freud deixa transparecer um sentimento de culpabilidade, aliado a sua submissão às autoridades, de maneira que ele enfim decide "perder seus escrúpulos" para fazer o que tinha de ser feito diante de seus superiores. 
Eu aprendi que nosso Velho Mundo é regido pela Autoridade como o Novo pelo dólar. Eu fiz as minhas primeiras reverências à Autoridade e então aguardei uma recompensa. (Freud, 1902, p. 306)

A promoção tão aguardada por Freud e adiada pela "conjuntura do momento", esse êxito, elevado em sua brincadeira ao nível de um triunfo político, era, contudo, "ilegítima";"rebaixada", por sua consciência, ao nível de um delito moral.

Freud pertencia, de fato, ao grupo mais ameaçado pelas novas forças: aquele dos judeus liberais vienenses que viam com ansiedade a chegada ao poder da nova direita. A vitória, nas eleições municipais de 1895, de Karl Lueger, que cantava seu anti-semitismo, juntamente com a denúncia do liberalismo e do capitalismo, criaria uma situação inextricável que faria soar o réquiem do liberalismo vienense. Em face do niilismo social e da propagação do ódio, os filhos da burguesia sentiam que não possuíam outra opção senão a de rejeitar as ilusões de seus pais e a de expressar outras aspirações.

Se as de Freud nos são conhecidas através de sua obra e de suas escolhas de vida, inúmeros de seus contemporâneos exprimiram as suas aspirações por caminhos diferentes: pelo sonho de uma terra prometida (reivindicação de um Estado judeu), como o visionário Theodor Herzl (1860-1904), que expôs a dinâmica de sua política num texto notável (Tagebücher, 1922, pp. 398-399), em que avaliou os pesos das realidades sociais e a impotência dos liberais de transformar o mundo, pela desconstrução do "eu" (moi); de Hugo von Hofmannsthal (1874-1929), na A carta a Lord Chandos, de 1902; ou, pior ainda, pelo suicídio, na negação ou conversão, em intelectuais habitados "pelo ódio de ser judeu", em que Karl Krauss (1874-1936) poderia ser considerado o representante mais notável. Krauss era um jornalista, escritor e polemista, a quem são atribuídos alguns aforismos célebres, como:"a psicanálise é essa doença de espírito que se considera, ela mesma, seu remédio" (ver L'Herne, 1975; Le Rider, 1994). Otto Weininger (1880-1903), de quem ele era próximo, era filho de um artesão judeu que renegou sua origem, tendo feito suas as teses anti-semitas de Houston Stewart Chamberlain (1855-1927), genro de Richard Wagner (1813-1883) e teórico da superioridade da "raça alemã". Em 1902 ele se converteu ao protestantismo e um ano mais tarde publicou Sexe et Caractère, verdadeiro manifesto da teoria da bissexualidade e de ódio às mulheres e aos judeus. No dia 3 de outubro do mesmo ano, suicidou-se com um tiro no coração num quarto alugado onde havia morrido Beethoven, seu compositor preferido. Freud considerava Weininger como um exemplo de neurose, inteiramente dominada pelos complexos infantis, dos quais o complexo de castração constitui, segundo ele, a raiz inconsciente do anti-semitismo, mas igualmente do desprezo pelas jovens mulheres. (Le Rider, 1982; Porge, 1994) 
Entre os escritores e autores dramáticos vienenses, Arthur Schnitzler, de quem Freud se sentia muito próximo, a ponto de o considerar seu "confrade" ou seu "duplo", é, certamente, aquele que mais explorou a relação entre as estratégias íntimas da psique e a imersão na história coletiva.

O combate pessoal de Freud contra a realidade política e social da Áustria transparecia claramente, se bem que indiretamente, na Interpretação dos Sonhos, à maneira de um Santo Agostinho que incluiria sua Confissões "na trama de Cidade de Deus" ou de um Rousseau que "fazia de suas Confissões uma história subliminar no coração do Discurso sobre a desigualdade" (Schorske, 1983, p. 179). A atenção dos historiadores da psicanálise é, então, atraída pelos diferentes elementos que ordenam os sonhos e que remetem ao passado recuado da infância, mas igualmente pela realidade do presente e pela grave crise que Freud atravessou nos anos 1890.

Sobre esse tema, a obra de referência é, sem dúvida, a de Didier Anzieu (Anzieu, 1988). A preocupação maior do autor concerne à psicanálise do gênio criativo e oferece um exemplo precioso da impossibilidade de separar a teoria psicanalítica da história da produção de seus conceitos e, portanto, de seus autores. Todas as citações, cartas ou textos autobiográficos de Freud se confundem com aqueles da criação da psicanálise. No entanto,"a verdade biográfica" não existe, segundo Freud, uma vez que o autor se obriga, inevitavelmente, às mentiras e aos segredos (ver a carta a A.Zweig de 31 de maio de 1939).

As frustrações, e tudo aquilo que ele considerava como fracassos desde o início de sua carreira, conduziram-no a atitudes de desesperança e amargura manifestas. $O$ fato que o obrigou a esperar dezessete anos, em vez de em torno de oito, para ser nomeado titular de uma cátedra na Universidade elevou ao seu máximo o isolamento intelectual e o mal-estar que ele sentia em relação à sociedade austríaca. Sua defesa diante das frustrações foi um recolhimento social e intelectual que, simultaneamente, lhe permitiu uma grande fecundidade científica. Desde 1896, ele era filiado à B'nai B'rith, organização fraternal judia, que o havia acolhido, discretamente, como homem de ciência, respeitando seu trabalho e, ao mesmo tempo, jamais o criticando ou tentando controlá-lo. Nessa mesma época, em 1896, a morte de seu pai, acontecimento que ele considerava como "o mais marcante, a perda mais pungente na vida de um homem", veio agravar a crise provocada pelos desafios profissionais, a dúvida a respeito de si-mesmo e a culpabilidade concernente às suas "reverências à autoridade". Os sonhos desse período, como a célebre "injeção de Irma" ou o "sonho do tio de barba loira", o testemunham. No terceiro dos sonhos narrados, aquele da "monografia botânica", Freud põe em cena seu pai exprimindo desconforto com relação à primeira atitude hostil dele, diante da bulimia livresca de seu filho, incômodo e frustração que poderiam ser compreen- 
didas como simétricas aos ressentimentos em face das hostilidades, para com ele, oriundas da intelectualidade austríaca.

Em agosto de 1898, Freud teve aquilo que denominaria "um sonho revolucionário", num momento em que a política possuía, ainda, lugar de preponderância na cena social (Schorske, 1983, pp. 187-188). No dia de seu sonho, Freud havia partido de férias com sua família para Ausee. Enquanto aguardava o trem, reconheceu na plataforma o conde Thun, que estava se dirigindo à residência de verão do Imperador, em Ischl, a fim de concluir os acordos econômicos preliminares austro-húngaros, conhecidos como os acordos de Ischl. O conde, apesar de não possuir a passagem do trem, se livrou do funcionário e se instalou no interior de um compartimento luxuoso. O"sonho do trem" pôs em cena, a partir desses restos diurnos, uma reunião universitária na qual Freud e Thun se confrontavam violentamente, a respeito de uma proposição do conde, que desdenhava dos nacionalistas alemães e da atividade militante dos estudantes.

Freud se identificava, no seu sonho, com Adolf Fischhof, estudante de medicina, que foi um dos que contribuíram com o desencadeamento da revolução de 1848. No sonho, ele punha em cena, igualmente, Viktor Adler, seu camarada e também rival na Universidade que, em 1898, se tornou líder da social-democracia austríaca. Fischhof e Adler eram exemplos vivos daqueles que podiam ser, ao mesmo tempo, médicos e homens políticos, possibilidade que Freud havia sempre recusado, ao explicar a escolha de sua profissão e o abandono de suas ambições políticas, após ter renunciado aos seus estudos de direito. Analisando esse sonho, Freud insistia mais sobre uma "mania de grandeza desde muito tempo reprimida" do que em sua coragem cívica (Schorske, 1983, pp.188-191). Mas, ali onde ele havia decidido centrar sua análise, na última seqüência, era quando seu pai entrava em cena, como um velho cego e impotente a quem seu filho estendia um urinol. Após ter relatado dois episódios de sua infância em que seu pai o havia repreendido por ter urinado na frente de seus parentes (com palavras humilhantes: "esse menino não serve para nada"), o Dr. Freud adulto inverte a situação, ajudando seu agonizante pai, dizendo-lhe, como Freud comenta: "você vê, eu me tornei alguém". O pai substitui o Primeiro Ministro Thun na plataforma e a vitória sobre o pai substitui sua vitória sobre a política. Schorske falará de "parricídio" em referência a essa parte do sonho. Freud comenta assim essa cena, numa nota de rodapé:

A atitude rebelde e crítica simboliza a revolta contra a autoridade paterna. Dizse que o príncipe é o pai do povo. O pai é a autoridade ancestral, a primeira; ele é, para a criança, a autoridade única.Todos os outros poderes sociais se desenvolvem a partir dessa autoridade prioritária (com a única ressalva do matriarcado). (Freud, citado por Schorske, 1983, p. 191) 


\title{
À guisa de conclusão
}

Meu objetivo neste artigo foi propor alguns aspectos de interação entre o direito e a psicanálise, e seus prolongamentos no campo da política, sob uma perspectiva epistemológica, histórica e conceitual. Longe de esgotar o assunto, essas considerações buscaram insistir no que resta inexplorado dessa relação complexa, por muitos qualificada de "ilegítima", mas cuja fecundidade e parentescos problemáticos tento demonstrar. Após tornar "legítima" uma colaboração que não parece evidente, e após retomar um Freud que se expressa freqüentemente como jurista, busquei dar ênfase aos limites dessas interações. Se, por um lado, a articulação do individual e do coletivo é uma constante na obra freudiana, e se ninguém contestaria o entrelaçamento entre "história privada" $e^{\text {"gran- }}$ de História", por outro lado, o método analógico entre processos psíquicos individuais e coletivos, que constituem uma problemática diferente, não encontrou um eco favorável. Seu lamarckismo explícito, relacionado à transmissão de traços mnêmicos nas massas, contribui, certamente, para isso, o que não impede que a história das idéias não deixe de se enriquecer com elas e que as dimensões metapsicológicas, sociológicas e políticas dessa parte da obra freudiana permaneçam, ainda, a ser exploradas.

\section{Law and psychoanalysis: An “illegitimate” relationship?}

\begin{abstract}
This article highlights some aspects of the interaction between law and psychoanalysis, including the extension of this interaction into the area of politics, from an epistemological, historical and conceptual point of view. Far from exhausting the topic, these considerations actually give emphasis to what still remains unexplored, concerning a complex relationship. It would be tempting to designate that relationship as "illegitimate", but I have nonetheless tried to demonstrate its versatility and its troubling affinities. After proving ultimately " legitimate " a collaboration which is far from self-evident, and revealing an overlooked aspect of Freud, who often exploits juridical language, this article points out the limits of the interaction between psychoanalysis and law. For, if the articulation of the individual and the collective is a constant in Freud's work, the analogical method correlating individual and collective psychical processes has never met with a favourable reception. The hypothesis about the transmission of mnemonic traces through the masses has doubtless contributed to that. Nevertheless, this part of Freud's work deserves to be further explored in its metapsychological, sociological and political dimensions. Moreover, the history of ideas and the history of psychoanalysis itself, in so far as it is a history of the production of works and of concepts and at the same time of their creators, as is the case with the Interpretation of dreams, would definitely be enriched by such an exploration.
\end{abstract}

Keywords: Applied psychoanalysis. History of psychoanalysis. Psychoanalysis and politics. Psychoanalysis and law. Alienation. 


\section{Droit et Psychanalyse: une relation “illégitime"?}

Résumé: Cet article se propose d'étudier quelques aspects des interactions entre droit et psychanalyse et leurs prolongements dans le domaine de la politique sous une perspective épistémologique, historique et notionnelle. Loin d'épuiser le sujet, ces considérations ne font qu'insister sur ce qui reste encore inexploré quant à une relation complexe que l'on serait tenté de qualifier $\mathrm{d}^{\prime}$ " illégitime ", mais dont on a essayé de démontrer la fécondité et les parentés troublantes. Après avoir rendu « légitime » une collaboration qui ne va pas de soi et révélé une face cachée de Freud, qui s'exprime souvent en juriste, on rappelle les limites de ces interactions. Car, si l'articulation de l'individuel et du collectif est une constante dans l'œuvre freudienne, la méthode analogique entre processus psychiques individuels et collectifs n'a pas trouvé un écho favorable. L'hypothèse de la transmission des traces mnésiques parmi les masses y a certes contribué. II n'empêche que cette partie de l'œuvre freudienne soit explorée davantage dans ses dimensions métapsychologiques, sociologiques et politiques. D'ailleurs, I'histoire des idées et l'histoire de la psychanalyse elle-même, en tant qu'histoire de la production des œuvres et des concepts et celle de leurs créateurs à la fois (comme c'est le cas pour L'Interprétation des Rêves), ne peut qu'en sortir enrichie.

Mots-clés: Psychanalyse appliquée. Histoire de la psychanalyse. Psychanalyse et politique. Psychanalyse et droit. Aliénation.

\section{Derecho y Psicoanálisis: ¿una relación ilegítima?}

Resumen: Este artículo se propone estudiar algunos aspectos de las interacciones entre el derecho y el psicoanálisis y sus prolongaciones en el campo político bajo una perspectiva epistemológica, histórica y conceptual. Lejos de agotar esta temática, las consideraciones insisten sobre lo que queda aun sin explorarse de una relación compleja que podría verse como "ilegítima" pero cuya fecundidad y parentesco llamativo yo intenté demostrar. Luego de haber vuelto "legítima" una colaboración que no es evidente y que revela una faceta oculta de Freud, quien se exprime seguido como jurista, este artículo recuerda los límites de esas interacciones. Porque si la articulación de lo individual y lo colectivo es una constante en la obra freudiana, el método analógico entre procesos psíquicos individuales y colectivos no ha encontrado un eco favorable. La hipótesis de la transmisión de huellas mnémicas en las masas ha ciertamente contribuido a ello. Lo que no impide que esa parte de la obra de Freud merezca ser explorada en sus dimensiones metapsicológicas, sociológicas y políticas. Por otro lado, la historia de las ideas y la historia del psicoanálisis mismo, en tanto historia de la producción de obras y conceptos así como a la vez la historia de sus creadores, como en el caso de La interpretación de los sueños, no puede más que terminar enriquecida.

Palabras-chave: Psicoanálisis aplicada. Historia del psicoanalisis. Psicoanálisis y política. Psicoanálisis y derecho. Alienación. 


\section{Referências}

Airut,J.P.(2006).Droit et mœurs: sur le concept oublié et oublieux de légitimité. In S. Tzitzis (Dir.), La mémoire, entre silence et oubli (pp. 376-454). Québec: Les Presses de I'Université Laval.

Anzieu, D. (1988). L'autoanalyse de Freud et la découverte de la psychanalyse (Vol. 2, 3a ed.) Paris: PUF.

Assoun, P.-L. (1987). L'École de Francfort. Paris: PUF.

Assoun, P.-L. (1990a). Freudisme et indifférentisme politique - objet de l'idéal et objet de la démocratie. Hermes, 5-6, 345-360.

Assoun, P.-L. (1990b). Le Freudisme. Paris, PUF.

Assoun, P.-L. (1995). Pater incertus, mater incognita. In L. Khaïat, Vérité scientifique, vérité psychique et droit de la filiation. Toulouse: Erès. (Colóquio de l'IRCID-CNRS, 9 a 11 de fevereiro de 1995)

Assoun, P.-L. (2002). Le vocabulaire de Freud. Paris: Ellipses.

Aulagnier, P. (1979). Les destins du plaisir. Aliénation, amour, passion. Paris: PUF.

Carroy, J., Ohayon, A., \& Plas, R. (2006). Histoire de la psychologie en France. Paris: La Découverte.

Christopoulou,V.P.(2005).La vérité en histoire et en psychanalyse. Tese de Doutorado, Universidade Paris 7 Denis Diderot, Paris.

Freud, S. (1911). Remarques psychanalytiques sur un cas de paranoïa (Dementia paranoïdes) décrit sous forme autobiographique. In OCF.P Fuvres complètes de Freud. Psychanalyse (Vol. 10, pp. 225-304). Paris: PUF.

Freud, S. (1912-1913). Totem et tabou. In OCF.P Fuvres complètes de Freud. Psychanalyse. (Vol. 11, pp. 189-386). Paris: PUF.

Freud, S. (1916). Les criminels par sentiment de culpabilité.Quelques types de caractère tirés du travail psychanalytique. In OCF.P CEuvres complètes de Freud. Psychanalyse (Vol. 15, pp. 13-40). Paris: PUF.

Freud, S. (1920). Au-delà du principe de plaisir. In OCF.P CEuvres complètes de Freud.Psychanalyse. (Vol. 15, pp. 273-338)Paris: PUF.

Freud, S. (1921). Psychologie des masses et analyse du Moi. In OCF.P CFuvres complètes de Freud. Psychanalyse (Vol. 16, pp. 1-84). Paris: PUF.

Freud, S. (1923). Le moi et le ça. In OCF.P CEuvres complètes de Freud. Psychanalyse (Vol.16, pp. 255-302). Paris: PUF.

Freud, S. (1927). L'avenir d'une illusion. In OCF.P Fuvres complètes de Freud. Psychanalyse (Vol. 18, pp. 141-197). Paris: PUF.

Freud,S. (1930). Le malaise dans la culture. In OCF.P. Guvres complètes de Freud. Psychanalyse (Vol. 18, pp. 245-333). Paris: PUF. 
Freud, S. (1939 [1934-1938]).Der mann moses und die monotheistische Religion: drei Abhandlungen (Vol. 16, pp. 103-236). Gesammelte Werke.

Freud, S. (1981). Considérations actuelles sur la guerre et la mort. In Essais de psychanalyse (p.25). Paris: Payot. (Trabalho original publicado em 1915)

Freud, S. (1984). Personnages psychopathiques à la scène. In Résultats, idées, problèmes (T. 1, pp. 123-129). Paris: PUF. (Trabalho original publicado em 1942 [1905-1906])

Freud, S. (1985). L'établissement des faits par voie diagnostique et la psychanalyse. In L'Inquiétante Étrangeté et autres essais (pp. 7-8). Paris: Gallimard. (Trabalho original publicado em 1906)

Freud, S. (1985). Vue d'ensemble des névroses de transfert, in OCF.P Fuvres complètes de Freud.Psychanalyse.(Vol.13, pp.281-302). Paris:PUF. (Trabalho original publicado em 1915)

Freud, S. (1988). Le mot d'esprit et sa relation à l'inconscient. Paris: Gallimard. (Trabalho original publicado em 1905)

Freud, S. (1989). La morale sexuelle civilisée et la maladie nerveuse des temps modernes. In La vie sexuelle (p. 33). Paris: PUF. (Trabalho original publicado em 1908)

Freud, S. (1989). Pour introduire le narcissisme. In La vie sexuelle (pp. 81-105). Paris: PUF. (Trabalho original publicado em 1914)

Freud, S. (1990). Remarques sur un cas de névrose obsessionnelle (L'homme aux rats). In Cinq psychanalyses (p. 251). Paris: PUF. (Trabalho original publicado em 1909)

Freud, S. (1991). Carta de 11 de março de 1902 à Fliess. In La naissance de la psychanalyse (p.306). Paris: PUF.

Freud, S. (1992). Actions compulsionnelles et exercices religieux. In Névrose, psychose et perversion (pp. 133-142). Paris: PUF. (Trabalho original publicado em 1907)

Freud, S. (1992). Un rêve utilisé comme preuve. In Névrose, psychose et perversion (pp. 199-208). Paris: PUF. (Trabalho original publicado em 1913)

Freud, S. (1992). Le roman familial des névrosés. In Névrose, psychose et perversion (pp. 157-160). Paris: PUF. (Trabalho original publicado em 1909)

L'Herne. (1975). Karl Kraus (número especial).

Laplanche, J., \& Pontalis, J.-B. (1967). Vocabulaire de la psychanalyse. Paris: PUF.

Le Rider, J. (1994). Modernité viennoise et crises de l'identité. Paris: PUF.

Le Rider, J. (1982). Le cas Otto Weininger. Racines de l'antiféminisme et de l'antisémitisme. Paris: PUF. 
Maître, J.(1995).L'Orpheline de la Bérézina,Thérèse de Lisieux (1873-1897). Essais de psychanalyse socio-historique. Paris: Les éditions du Cerf.

Mijolla-Mellor, S. (2002a). Alienation.In A.Mijolla (Ed.),Dictionnaire international de la psychanalyse (p.40). Paris: Calmann-Lévy.

Mijolla-Mellor, S. (2002b). Criminologie et psychanalyse. In A. Mijolla (Ed.), Dictionnaire international de la psychanalyse (pp. 381-383). Paris: CalmannLévy.

Mijolla-Mellor, S. (2002c). Psychanalyse appliquée/interactions de la psychanalyse. In A.Mijolla (Ed.),Dictionnaire international de la psychanalyse (p. 1292). Paris: Calmann-Lévy.

Mijolla-Mellor, S. (2004).La recherche en psychanalyse à l'université. Recherches en psychanalyse, (1), 27-47.

Plon, M. (2007). La psychanalyse dans son temps. Raison politiques, 25, 89-99.

Porge, E. (1994). Vol d'idées? Paris: Denoël.

Porte, M. (1998). Pulsions et politique. Une relecture de l'événement psychique collectif à partir de l'œu vre de Freud. Paris: L'Harmattan.

Roudinesco, E., \& Plon, M. (2000).Dictionnaire de la psychanalyse (pp.853-857). Paris:Fayard.

Schorske, C.E. (1983).Vienne, fin de siècle. Paris: Le Seuil.

Stern, A.L. (2004).Le savoir deporté. Camps, histoire, psychanalyse.Paris:Le Seuil.

Trapet, M. A., \& Trapet, M.D. (1999). Freud, théoricien du désaveu de paternité, Topique, 70, 49-59.

Trapet, M. D. (1998). Le droit dans l'œuvre de Freud. Tese de Doutorado, Universidade Paris VII, Paris.

Trapet, M. D. (2002). Droit et psychanalyse. In A. Mijolla (Ed.), Dictionnaire international de la psychanalyse. Paris: Calmann-Lévy.

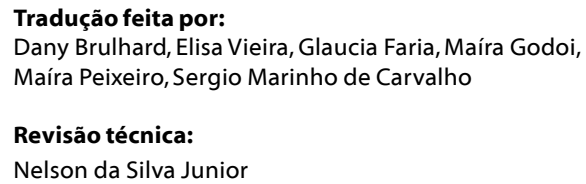

Recebido em: 16/07/2007

Aceito em: 24/09/2007 